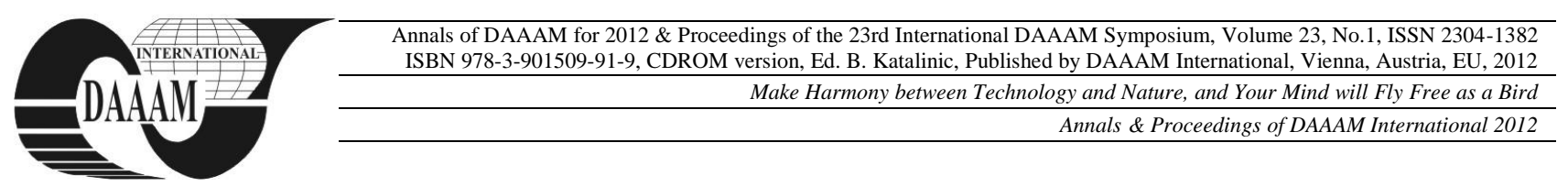

\title{
SUBSURFACE DAMAGE IN GRINDING SILICON CERAMICS
}

\author{
DOBRESCU, T[iberiu] G[abriel]; PASCU, N[icoleta] - E[lisabeta]; \\ OPRAN, C[onstantin] \& BUCURESTEANU, A[nca] M[onica]
}

\begin{abstract}
Subsurface damage evaluation is performed using a combination of scanning electron microscopy and damage inspection techniques on silicon nitride and silicon carbide ground by single point diamond tools and diamond wheels. Two forms of surface damage are indentified, material pulverization in the superficial layer forming o powder regime and void geration in the subsurface layer. Material pulverization is observed that forms a powder-regime layer on a ground work-piece surface, which is the dominant materialremoval mechanism up to certain depth of cut. Underneath the powder-regime layer, damage is identified in the ground workpiece, and is assessed and characterized with respect to type of workpiece material and grit size of grinding wheels.

Keywords: grinding, material-removal, powder-regime, depth of cut, silicon ceramics
\end{abstract}

\section{INTRODUCTION}

In a grinding process, each protruding abrasive grain on a grinding wheel generates an intense local stress field upon contacting the workpiece surface. This stress field causes irreversible material deformation in die form of dislocation, cracks and voids.

The material-removal mechanism is usually classified into two categories: brittle fracture and plastic deformation [1].

Brittle fracture, analogous to indentation of a brittle material by a hard indenter, involves two principal crack systems: lateral cracks which are responsible for material removal, and median cracks, for strength degradation. In brittle fracture, material-removal is accomplished through void and crack nucleation and propagation, chipping or crushing [2].

Plastic deformation is similar to the chip formation process in metal grinding, which involves scratching, plowing, and chip formation. The material is removed in the form of severely sheared machining chips. The strength, hardness, and fracture toughness of the work material are the governing factors that control the extent of brittle fracture and plastic deformation.

Grinding process is an inherently damaging process since the abrasive grains are forced into the surface. It is therefore not surprising that the grinding operation causes decreased mechanical strength of the machined components, an effect frequently reported in the literature [2], [3], [4], [5] and [6].

In the grinding of silicon ceramics, material-removal may be based on such mechanism as crushing, chipping or fracture, pulverization, and plastic deformation. In dealing with precision grinding processes, where the depth of cut is normally in the submicron range, crushing and chipping or fracture mechanism can be excluded from this list.

Material pulverization occurs when ceramic grains sized in micrometers are pulverized during grinding into finer grains in submicron range or even smaller. Pulverization can occur along the cleavage planes and slip systems of ceramic grain, leading to the formation of a large number of finer grains. More surfaces and a larger specific surface area are thereby generated [7].

Subsurface damage caused by a grinding process can be a function of numerous factors including material properties, grinding conditions, grinding wheel parameters, and grinding wheel truing and dressing condition. It was reported that the brittleness, which is defined as the ratio of hardness to toughness $H / K_{c}$ of a material, was a governing factor affecting the penetration depth of subsurface damage [8].

In 1987, Inasaki [9] proposed a critical condition for the initiation of subsurface damage:

$$
C_{\min }=\zeta\left(\frac{K_{c}}{H}\right)^{2}
$$

Critical condition was extended to a grinding situation by Bifano who advanced a model to correlate the critical grit depth of cut with material properties.

The model is described by a simple power-law equation [3]:

$$
d_{c}=0.15\left(\frac{E}{H}\right)\left(\frac{K_{c}}{H}\right)^{2}
$$

Under a given grinding condition, subsurface damage is solely determined by material properties.

This paper presents an analytical model for the prediction of subsurface damage of ceramics subjected to grinding. The model correlates subsurface damage to the type of workpiece material and grinding parameters.

The results of damage prediction using the analytical model are verified by the experiments.

\section{DAMAGE PREDICTION MODEL}

In a material-removal process, the response of the material is to generate the highest possible resistance to the external machining system in order to maintain its natural structure. The highest possible resistance corresponds to the highest possible energy consumption by the material, which determines the most favorable material-removal mechanisms in a machining process. 
Based on this energy argument, pulverization is considered to be the most favorable material-removal mechanism in grinding of ceramics at minute depth of cut.

Grinding damage is induced by grinding forces, predominantly the normal force.

The normal force on a single grit is proportional to the mean chip cross-sectional area $a_{m}$ that can be expressed as [9]:

$$
F_{n}=\alpha K_{O} h_{g}^{1-\varepsilon}
$$

Where $\alpha$ is the ratio of the normal to tangential grinding forces, and is a constant for a given grinding condition; $\mathrm{K}_{\mathrm{o}}$, and $\varepsilon$ are constants to be determined by the material properties of a workpiece; and $h_{g}$ is the maximum grit depth of cut that is given by the following equation:

$$
h_{g}=\sqrt{\frac{4 v}{\operatorname{VrC} \sqrt{\frac{h_{w}}{D}}}}
$$

Where $h_{w}, D, v$, and $V$ are wheel depth of cut, wheel diameter, workpiece speed, and wheel surface speed; C the grit surface density that is defined as the number of active points per unit area of the wheel surface, and $r$ is the ratio of chip width to average undeformed chip thickness. On the other hand, a correlation between the subsurface damage depth and externally applied load can be obtained [9]:

$$
F_{n} \propto \xi^{m}
$$

The exponent $\mathrm{m}$ is in the range of $1 / 2 \leq \mathrm{m} \leq 3 / 2$ for different loading conditions. By substituting (5) into (3), we then obtain:

$$
\xi=\left(A h_{g}\right)^{B}
$$

In which $\mathrm{A}$ and $\mathrm{B}$ are factors to be determined by material properties and grinding conditions. It is assumed that $\mathrm{B}$ is predominantly a function of material properties, and $\mathrm{A}$ function of experiments, and the factors $\mathrm{A}$ and $\mathrm{B}$ are to be determined by experiments.

\section{EXPERIMENTAL PROCEDURES}

A precision grinding machine equipped with an aerostatic spindle and aerostatic slideway was used for the experimental work. The workpiece was then shaped by a cylindrical grinding machine equipped with diamond grinding wheels and polished to remove the layers damaged by the grinding processes [10].

Polishing was done by diamond pastes with grain sizes ranging from $15 \mu \mathrm{m}$ (for rough polishing) to 0.25 $\mu \mathrm{m}$ (for fine polishing). In diamond-wheel grinding, a ceramic workpiece with dimensions $30 \times 5 \times 5 \mathrm{~mm}$ was fixed on to a steel surface plate. Three rectangular surfaces of each specimen were polished with $15 \mu \mathrm{m}$ diamond paste to remove possible damage induced by the previous procedures.

The diamond wheel grinding tests were carried out under the following conditions:

1. Method: wet surface grinding;
2. Grinding wheel: SD 80-N50M, SD 140-N75M, SD 400-N75M;

3. Grit mesh size: \#60-80, \#140-170, \#325-400;

4. Wheel speed: $1600 \mathrm{~m} / \mathrm{min}$;

5. Table speed: $1.4 \mathrm{~m} / \mathrm{min}$;

6. Wheel depth of cut: $15 \mu \mathrm{m}$;

7. Grinding width: $5 \mathrm{~mm}$;

8. Coolant application: soluble type $2 \%$ dilution.

\begin{tabular}{|l|c|c|}
\hline & $\mathbf{S i}_{\mathbf{3}} \mathbf{N}_{\mathbf{4}}$ & $\mathbf{S i C}$ \\
\hline Density, g/cm & 3.28 & 3.15 \\
\hline Grain size, $\mu \mathrm{m}$ & $2-3$ & 5 \\
\hline Vickers hardness, Mpa & 17.9 & 31 \\
\hline Fracture toughness, MN/m ${ }^{3 / 2}$ & 6.6 & 3.6 \\
\hline Flexure strength, Mpa & 800 & 490 \\
\hline Brittleness, $/ \mathrm{m}^{1 / 2}$ & 2,700 & 8,300 \\
\hline
\end{tabular}

Tab. 1. Physical properties of the silicon ceramic materials

\begin{tabular}{|c|c|c|c|}
\hline $\begin{array}{c}\text { Diamond } \\
\text { wheel }\end{array}$ & $\begin{array}{c}\text { Mean grit } \\
\text { size, } \boldsymbol{\mu m}\end{array}$ & $\begin{array}{c}\text { Grit surface } \\
\text { density, } \\
\text { grits/mm }\end{array}$ & $\begin{array}{c}\text { Maximum } \\
\text { grit depth of } \\
\text { cut, } \boldsymbol{\mu m}\end{array}$ \\
\hline SD 80-N50M & 230 & 3.1 & 0.91 \\
\hline SD 140-N75M & 100 & 6.3 & 0.64 \\
\hline SD 400-N75M & 40 & 17.4 & 0.38 \\
\hline
\end{tabular}

Tab. 2. Grinding wheel parameters

The ground surface and subsurface layers were observed and measured using SEM (Scanning Electron Microscopy) and a surface profilometer. Silicon nitride (Si3N4) was prepared using the hot-press technique, while silicon carbide ( $\mathrm{SiC}$ ) by the pressureless sintering technique. Table 1 lists the physical properties of these materials.

Table 2 gives the values of the mean grit size and grit surface density and the maximum grit depth of cut of the diamond wheels.

\section{EXPERIMENTAL RESULTS}

Grains on the surface layer of a ceramics can be pulverized into much finer ones (submicron sizes or smaller) by grinding through intergranular and/or transgranular microcracking, and form a powder regime.

The thickness of a powder regime varied along the ground surface due to the non-uniform distribution of abrasive grits on wheel surface. The powder regime thickness was measured over a cross-section that was divided into 10 identical parts.

The SD80-N50M wheel generated the largest amount of powder regime on silicon nitride which was followed by the SD140-N75M and SD400-N75M wheels. The experimental results reveal that a grinding wheel of a larger grit size generates more powder regime than does that generated by the wheel with an average grit size of $230 \mu \mathrm{m}$ was more than three times of that by the wheel with an average grit size of $40 \mu \mathrm{m}$. 


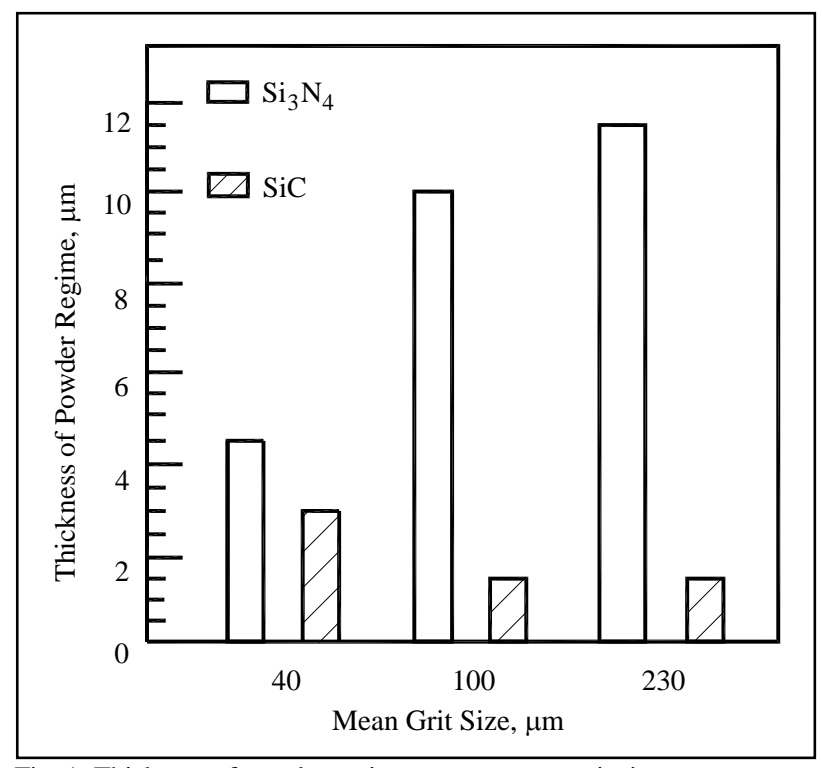

Fig. 1. Thickness of powder regime versus means grit size

In Fig. 1 is shown the thickness of powder regime versus means grit size.

Accordingly the number of active cutting points per unit area of the SD400-N75M wheel was 5-6 times that of the SD80-N50M wheel, resulting in a large difference in the grit depth of cut. The grit depth of cut for the SD400-N75M wheel was less than one-third of than for the SD80-N50M diamond wheel.

The amount of powder regime generated on silicon nitride was the largest, followed by silicon carbide using the same grinding wheel.

Grinding induced damage was found in the subsurface layers of all the silicon ceramics. The damage inspection was performed using SEM combined with the etching technique. The damage aligns them in the grinding direction, forming damage lines.

Both clustered and scattered damages were generated in silicon nitride when the SD140-N75M and SD80N50M wheels were used for grinding, however, only scattered damage was formed in these materials when the SD400-N75M wheel was used. Mainly scattered damage was found in the subsurface of silicon carbide regardless of the grinding wheels.

These observations indicate that whether clustered or scattered damage forms depend on the brittleness of workpiece materials, and the grinding parameters. A material with a high brittleness value (silicon carbide), tends to have more scattered damage, while a material having a low brittleness value (silicon nitride), tends to have more clustered damage.

In Fig. 2 is shown the maximum depth of damage distribution was quantitatively measured against the grit size of the grinding wheels used. Silicon nitride had the largest penetration depth of damage among all the silicon ceramics under the same grinding conditions.

In using the SD80-N50M wheel, the depth of damage distribution was as large as $40 \mu \mathrm{m}$ in silicon nitride, and less in silicon carbide. With a decrease in grit size, there was found to be a decrease in the depth of damage penetration for silicon nitride, but very little decrease for silicon carbide.

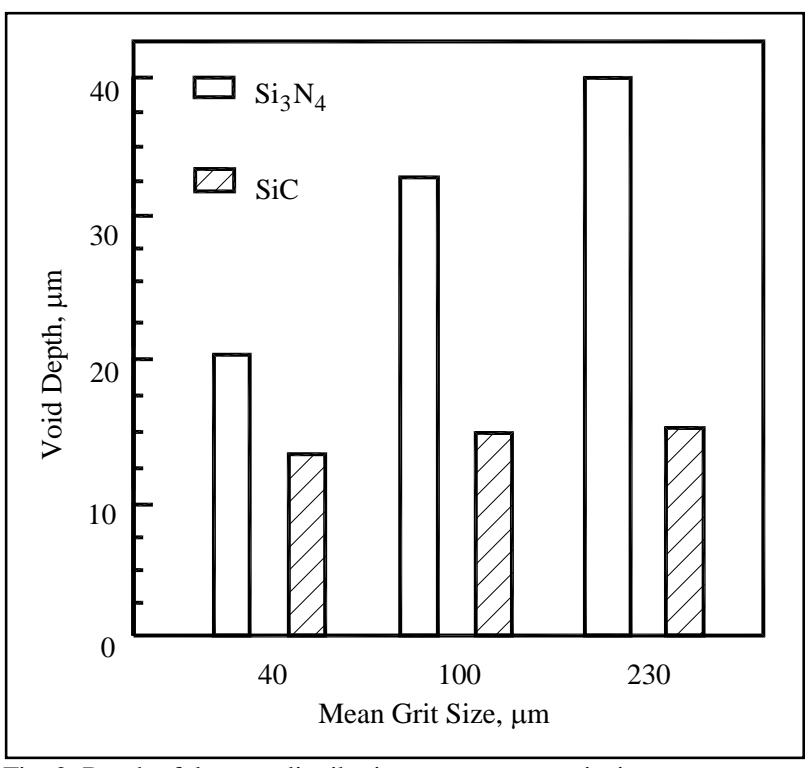

Fig. 2. Depth of damage distribution versus mean grit size

It should be noted that two factors $\mathrm{A}$ and $\mathrm{B}$ are correlated with material properties, grinding wheel parameters, grinding, truing, and dressing conditions. These factors can be determined based on the experimental results: $A=200$ and $B=1 / \log \left(\lambda \mathrm{H} / \mathrm{K}_{0}\right)$, where $\lambda=10^{-2} \mathrm{~m}^{1 / 2}$ is a constant. By substituting the factors $\mathrm{A}$ and $\mathrm{B}$ into (6), the proposed model then becomes:

$$
\xi=\left(200 h_{g}\right)^{1 / \log \left(\lambda \frac{H}{K_{c}}\right)}
$$

Equation (7) correlates the damage depth with the brittleness of silicon ceramics, and the grit depth of cut of a wheel. The relationship illustrates that a low level of damage depth is obtained in a material with a high brittleness value, while a high level of damage depth in a material with a low brittleness value.

\section{DISCUSSION}

A model has been proposed for predicting subsurface damage. Based on this model in Fig. 3 and Fig. 4 are plotted variations of damage depth with the maximum grit depth of cut and brittleness of workpiece materials.

The predicted damage depths show good agreement with those of the experiments. According to this model:

a. Damage depth exponentially increases with increasing grit depth of cut.

b. Damage depth increases with a decrease of material brittleness.

c. As the grit depth of cut decreases, the difference in damage depth among these materials tends to disappear.

A question remains is: why a more brittle material such as silicon carbide has a larger number of scattered voids with a relatively small penetration depth, and a less brittle material such as silicon nitride has a smaller number of scattered voids with a relatively large penetration depth? To answer this question, we may use (1) for critical damage size, and the following equation 
for the minimum load to propagate a critical damage [10].

$$
F_{\min } \propto\left(\frac{K_{c}}{H}\right)^{3} K_{c}
$$

For silicon carbide, a $2 \%$ load is needed to produce a critical damage of $10 \%$ in size with respect to silicon nitride. This is to say that for a given grinding condition, the population of critical damage would be much larger, but the depth of the damage would be much smaller in silicon carbide than silicon nitride. Although the more brittle material shows less depth of damage, the number of cracks or voids in much greater than is the case for the less brittle material.

Nevertheless, Veldkamp [11] demonstrated that the critical scratching load to initiate a crack complied with the same expression as (8) if the scratching hardness was substituted for the indentation hardness. Based on the discussion, it has became clear that for a given grinding condition, hardness and fracture toughness are the predominant factors in determining whether subsurface damage contains a large number of scattered voids with relatively small penetration depth as in the case of silicon carbide, or a small number of clustered voids with relatively large penetration depth as in the case of silicon nitride. The former may indicate that the energy given by an abrasive grit into a workpiece is dissipated in a distributed manner, while the latter in a concentrated manner.

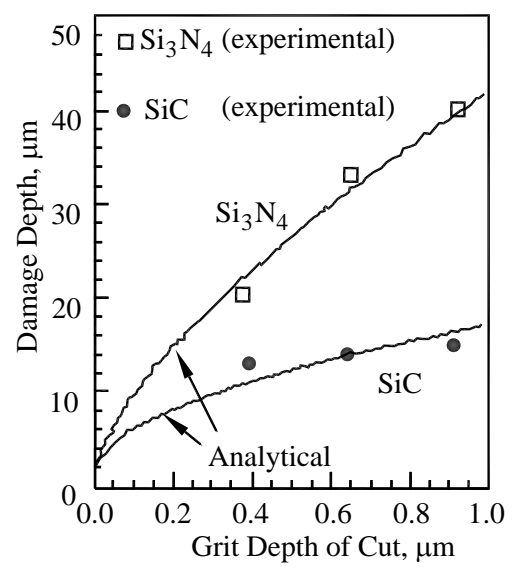

Fig. 3. Damage depth versus maximum grit depth of cut

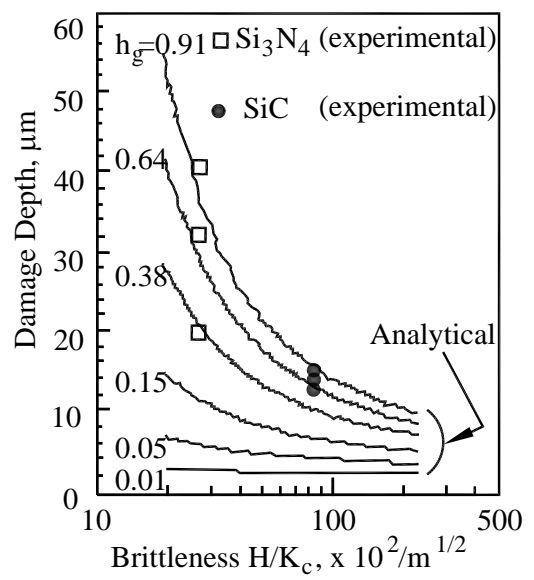

Fig. 4. Damage depth versus brittleness of silicon ceramics
The shear stress is not released until a certain level of stress concentration is reached, which results in a stress relaxation at a relatively long range. This process would result in clustered voids in a large penetration depth but a small number.

\section{CONCLUSIONS}

Subsurface damage has been evaluated on silicon nitride and silicon carbide ground by diamond wheels with various grit sizes. Clustered damage is induced in the less brittle materials, while scattered damage is in all the silicon ceramic materials tested. Based on the research described in this paper, the following conclusions can be made:

1. The larger an abrasive grain is, the more powderregime it generates.

2. Subsurface damage is related to the properties of silicon ceramic materials, specifically brittleness.

3. The penetration depth of subsurface damage is predictable using an analytical model (7).

4. The penetration depth of subsurface damage increase with a decrease of material brittleness.

5. The penetration depth of subsurface damage increase with an increase of the maximum grit depth of cut.

\section{REFERENCES}

[1] Conway, J. C. \& Kirchner, H. P. (1986). Crack Branching as a Mechanism of Crushing During Grinding, Journal of American Ceramic Society, No. 69, 1986, pp. 603-607

[2] Kirchner, H, P. (1984). Damage Penetration at Elongated Machining Grooves in Hot-Pressed $\mathrm{Si}_{3} \mathrm{~N}_{4}$, Journal of American Ceramic Society, No. 67, 1984, pp. 127-132

[3] Bifano, T. G.; Dow, T, A. \& Scattergood, R. O. (1991). DuctileRegime Grinding: A New Technology for Machining Brittle Materials, Journal of Engineering for Industry, No. 113, 1991, pp. 184-189

[4] Ito, M.; Nakamura, M. \& Kenematsu, S. (1989). Machining of Fine Ceramics, Journal of Japan Society of Precision Engineering, No. 52, 1989, pp. 403-408

[5] Dobrescu, T.; \& Anghel, F. (2008). Surface grinding method of silicon wafers, Annals of DAAAM for 2008\& Proceedings of 19th, 22-25 october 2008, Trnava, Slovakia ISSN1726-9679, ISBN 978-3-901509-68-1, Katalinic, B. (Ed.), pp. 0395-0396, Publisher by DAAAM International, Austria

[6] Nakamura, M.; Hirai, Y. \& Kubo, K. (1986). Surface Damage in Ground Silicon Carbide Ceramics, Journal of Ceramic Society of Japan, No. 94, 1986, pp. 683-688

[7] Dobrescu, T.; Enciu, G. \& Nicolescu, A. (2009). Selection of process parameters in grinding ceramics, Annals of DAAAM for 2009\& Proceedings of 20th, 25-28 november 2009, Vienna, ISSN1726-9679, ISBN 978-3-901509-70-4, Katalinic, B. (Ed.), pp. 0361-0362, Publisher by DAAAM International, Austria

[8] Zhang, B. \& Howes, T. D. (1994). Material Removal Mechanisms in Grinding Ceramics, Annals of the CIRP, No. 43, 1994, pp. 305308

[9] Inasaki, I. (1987). Grinding of Hard and Brittle Materials, Annals of the CIRP, No. 36, 1987, pp 1-9

[10] Dobrescu, T. (1998). Cercetări prind optimizarea maşinilor de superfinisat material fragile, Ph.D. Dissertation, Machine and Manufacturing Systems Department, University Politehnica of Bucharest, Romania

[11] Veldkamp, J. D. B. (1983). Crack Formation During Scratching of Brittle Materials, Fracture Mechanics of Ceramics, Vol. 5 , 1983, pp. 273-301 